\title{
Account
}

\section{Ionic Liquids: An Environmentally Friendly Media for Nucleophilic Substitution Reactions}

\author{
Yogesh R. Jorapur and Dae Yoon Chi' \\ Deparment of Chemisty, Inha University, Inchon 402-751, Korea. "E-mail: dvchi@inha.ackr \\ Received November 17, 2005
}

\begin{abstract}
Ionic liquids are alternative reaction media of increasing interest and are regarded as an eco-friendly altematives, of potential use in place of the volatile organic solvents typically used in current chemical processing methods. They are emerging as the smart and excellent solvents, which are made of positive and negative ions that they are liquids near room temperature. The nucleophilic substitution reaction is one of the important method for inserting functional groups into a carbon skeleton. Many nucleophilic substitution reactions have been found with enhanced reactivity and selectivity in ionic liquid. In this review, some recent interesting results of nucleophilic substitution reactions such as hydroxylations, ether cleavages, carbon- $\mathrm{X}$ (X $=$ carbon, oxygen, nitrogen, fluorine) bond forming reactions, and ring opening of epoxides in ionic liquids are discussed.
\end{abstract}

Key Words : Ionic liquid, Nucleophilic substitution reaction, $S_{\wedge} 2$, Reaction media

\section{Introduction}

Most of the actual chemical reactions in a synthesis usually involve incorporation of new functional groups or functional group exchanges. The nucleophilic substitution (S`) reaction is a powerful method for inserting functional groups into a carbon skeleton. ${ }^{1}$ In 1935, Hughes and Ingold built a broad theory of nucleophilic aliphatic substitution, which proceeds by two different mechanisms named bimolecular nucleophilic substitution $\left(\mathbf{S}_{\wedge} 2\right)$ reaction and unimolecular nucleophilic substitution $\left(\mathbf{S}_{\times} 1\right)$ reaction. ${ }^{2}$ The S -2 reactions follow second order kinetics with inversion of configuration, where as $\mathrm{S} \backslash 1$ reactions follow first order kinetics with racemization. Solvation is the key to most nucleophilic reactions.

Solvent is ubiquitous feature of moden industry and everyday life with the current usage of volatile organic compounds (VOCs) worldwide is around $£ 4,000,000,000$ per arnum and is one among the heavily implicated in causing change to the global climate. Today's chemist is well-aware of the global warming disaster and is prepared for designing the synthetic methodologies with high atom

Yogesh R Jorapur was born in Dombivli, Thane, Maharashira, India in 1976. He received a B.Sc. (Chemistry) degree in 1998 from Mumbai Lniversity and M.Sc. (Organic Chemistry) degree in 2000 from Pune Lniversity. He recently received his Ph.D degree under the superyision of Professor Dae Yoon Chi, Department of Chemistry, Medicinal Chemistry Lab, Inha University, Inchon, Korea. His research interest is mainly focused on the applications of Jonic liquids and Polymer-supported Ionic liquids as environmentally friendly reaction media. E-Inail: vogesh_inhauniagyahoo.co.in.

Dae Yoon Chi (b. 1955) received his B.Sc. degree in Chemistry at Sogang Lniversity (1977), M.Sc. degree in Chemistry at KAIST in economy. In order to gain true harmony, economic progress and environnental progress must go hand-in-lhand.

Ionic liquids (ILs) are emerging as smart and excellent solvents, which are made of positive and negative ions that pack so poorly together that they are liquids near room temperature. ${ }^{+}$They offer significant properties ${ }^{5}$ such as negligible vapor pressure, high themnal stability, lack of inflammability, decent solubility for organic, inorganic and organometallic compounds, and non-coordinating but good solvating ability. Apart from these features each IL shows unique chemical and physical property by proper varying its cation and anion. ${ }^{\circ}$ As reviewed by Song ot al., switching from an organic solvent to an ionic liquid often results in a significant improvement in catalytic performance (e.g., rate acceleration, (enantio)selectivity improvement and an increase in catalyst stability). Thus, catalysts having polar or ionic character in the ionic liquids can easily be immobilized without additional structural modification and thus the ionic solutions containing the catalyst can easily be separated from the reagents and reaction products, and then, be reused.

The ILs known till date comprise organic tetraalkylammo-

1979 and Ph.D. from University of Jllinois at Urbana-Champaign (1986) under the supervision of Professor John A. Katzenellenbogen. From 1986-1988, he worked at University of California Berkeley as a post-doctoral research fellow under Professor John E. Hearst and Professor Henry Rapoport. During 1979-1982 and 1988-1992, he worked as a research scientist at KIST. He also worked as a Director of PET Center of Samsung Medical Center during 1994-1995. He moved to Inha University as an Associate Professor in 1995, and then, he was promoted to full Professor in 2000 (http://med-chem.inha.ac.kr). He was one of National Research Laboratory directors $(2002-2005)$ and CEO of FutureChein Co. Ltd., (http:/ www futurechem.co.kr). 


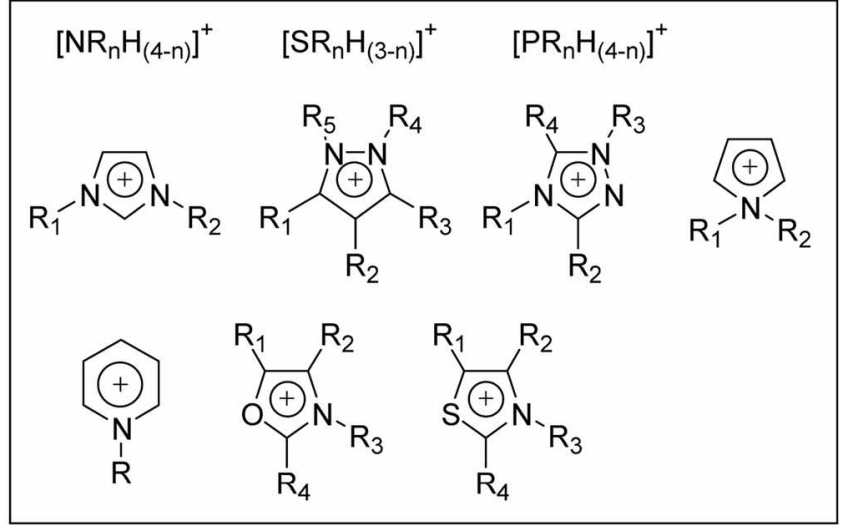

Figure 1. Cation types in Ionic Liquids.

nium, trialkylsulphonium, tetraalkylphosphonium, 1,3-dialkylimidazolium, $N$-alkylpyridinium, $N, N$-dialkylpyrrolidinium, $N$-alkylthiazolium, $N . N$-dialkyltrizolium, $N . N$ dialkyloxazolium, or $N, N$-dialkylpyrazolium cations (Figure 1). ${ }^{8-1}$ The anions $\mathrm{s}^{\text {td }}$ are either organic or inorganic, including: $\mathrm{BF}_{4,}{ }^{18} \mathrm{PF}_{6 .}{ }^{19} \mathrm{CF}_{3} \mathrm{CO}_{2}{ }^{20} \mathrm{SbF}_{6}{ }^{2122} \mathrm{ZnCl}_{3}, \mathrm{CuCl}_{2}, \mathrm{SnCl}_{3}$. $\mathrm{N}\left(\mathrm{CF}_{3} \mathrm{SO}_{2}\right)_{2}{ }^{2,3-26} \mathrm{~N}\left(\mathrm{C}_{2} \mathrm{~F}_{5} \mathrm{SO}_{2}\right)_{2}, \mathrm{~N}\left(\mathrm{FSO}_{2}\right)_{2},{ }^{23} \mathrm{C}_{(2}\left(\mathrm{CF}_{3} \mathrm{SO}_{2}\right)_{3},{ }^{23} 3+26$ $\mathrm{CF}_{3} \mathrm{SO}_{3}{ }^{232-25} \mathrm{CH}_{3} \mathrm{SO}_{3}, \mathrm{CH}_{3} \mathrm{CO}_{2}{ }^{60} \mathrm{OTs}, \mathrm{NO}_{2},{ }^{64} \mathrm{NO}_{3},{ }^{60} \mathrm{HSO}_{4}$, carborane, and halides ${ }^{20}$; polynuclear anions including: $\mathrm{Al}_{2} \mathrm{Cl}_{7}, \mathrm{Al}_{3} \mathrm{Cl}_{10}, \mathrm{AuCl}_{7}, \mathrm{Fe}_{2} \mathrm{Cl}_{7}, \mathrm{Sb}_{7} \mathrm{~F}_{11}$. In the near future, the list of cations and anions will be extended to a nearly limitless number.

We do not discuss regarding the synthesis of various classes of ILs, as this is outside the scope of this review. This review is restricted to aliphatic bimolecular nucleophilic substitution $\left(\mathrm{S}_{\kappa} 2\right)$ reactions and will summarize the recent research on the applications of ILs in this context.

\section{Ether Cleavage}

Usually, cleavage of aromatic alkyl ether bonds to regenerate phenols is achieved by treatment with boron tribromide, hydrobromic acid, or aluminium chloride. Recently, cleavage of aromatic methyl ethers by chloroaluminate ionic

Table 1. Cleavage of Aromatic Methyl Ethers by [TM $\mathrm{TH}]\left[\mathrm{AL}, \mathrm{Cl}_{7}\right]$ (IL)

entry

"Determined by GC and NMR spectroscops. The reaction mixture was wamed to rellux and the reaction was monitored by GC and TLC until the reaction was complete. "Indicates which methoxyl group is cleaved predominantly,
Table 2. Demethylation of 2-Methoxynaphthalene with Various Protic Acids in [bmim] $\left[\mathrm{BF}_{+}\right]^{\prime \prime}$

\begin{tabular}{cccccc} 
[bmim][Br], [bmim][BF & protic acid, $115^{\circ} \mathrm{C}$ \\
\cline { 3 - 6 } entry & protic acid & equiv & $\begin{array}{c}\text { [bmim][Br] } \\
\text { (equiv) }\end{array}$ & time $(\mathrm{b})$ & $\begin{array}{c}\text { yield } \\
(\%)\end{array}$ \\
\hline 1 & $\mathrm{HBr}(47 \%)$ & 5 & - & 7 & 96 \\
2 & $\mathrm{HBr}(47 \%)$ & 2 & - & 9 & 97 \\
3 & $p-\mathrm{TsOH}$ & 2 & 2 & 22 & 97 \\
4 & $p-\mathrm{TsOH}$ & 3 & 2 & 22 & 30 \\
5 & $\mathrm{MsOH}$ & 3 & 3 & 14 & 97 \\
6 & $\mathrm{HCl}(35 \%)$ & 3 & 3 & 22 & 93 \\
7 & $\mathrm{H}_{2} \mathrm{SO}_{4}(50 \%)$ & 3 & 3 & 22 & 93 \\
\hline
\end{tabular}

"All reactions were carried out on a 1.0 mmol reaction scale of $2-$ methoxy naphthalene $1 \mathrm{in} 1.0^{\mathrm{mL}}$ of $[\mathrm{b}$ mim $]\left[\mathrm{BF}_{4}\right]$ at $115^{\circ} \mathrm{C}$. 'Tsolated yield.

liquids, such as trinethylammonium chloroaluminate ([TMAH] $\left[\mathrm{Al}_{2} \mathrm{Cl}_{7}\right]$ ) and $[\mathrm{bmim}]\left[\mathrm{Al}_{2} \mathrm{Cl}_{7}\right]$, have been reported (Table 1). ${ }^{27}$ This method exhibited a remarkably high selectivity in comparison with aluminium chloride. In addition, the reaction time is drastically shortened.

Another dealkylation of ethers in ionic liquid was achieved by using the enhanced halide nucleophilicity of an ionic liquid anion in the presence of classical acid. ${ }^{28}$ This combination of the nucleophilicity of an ionic liquid anion (bromide of [bmim] $\mathrm{Br}]$ ) and the lower acidity of $p$ toluenesulfonic acid was first attempted for the cleavage of ether. As shown in Table 2, the demethylation reaction of 2methoxynaphthalene with concentrated hydrobromic acid alone with 5 or $2 \mathrm{mmol}$ equiv in $[\mathrm{bmim}]\left[\mathrm{BF}_{\downarrow}\right]$ was completed in $7 \mathrm{~h}$ and $9 \mathrm{~h}$, affording 2-1naphthol in excellent yields ( $96 \%$ and $97 \%$, respectively). The same reaction with a lower mole ratio ( $1.1 \mathrm{mmol}$ equiv) also fumished the desired product in good yield, but the reaction rate decreased significantly and required longer reaction time to complete ( $32 \mathrm{~h}, 94 \%$ ). Use of other protic acids, such as $p$-toluenesulfonic acid $(p-\mathrm{TsOH})$, methanesulfonic acid $(\mathrm{MsOH})$, hydrochloric acid and sulfuric acid alone in [bmim] $\left[\mathrm{BF}_{+}\right]$, resulted in poor conversion $(30,27,25$, and $29 \%$, respectively). This difference can be attributed to the catalytic influence of bromide ion concentration on the rate of ether cleavage. The combination of ionic liquid $[\mathrm{bmim}][\mathrm{Br}]$ and $p-$ toluenesulfonic acid at about $115^{\circ} \mathrm{C}$ afforded the demethylated product within $22 \mathrm{~h}$ in excellent yield $(97 \%)$.

\section{Carbon-Carbon Bond Forming Reactions}

A. Meldrum's Acid Alkylation. The alkylation of active methylene compounds are very important methods for the formation of carbon-carbon bond in organic synthesis. ${ }^{29}$ Room temperature ionic liquid (RTIL) such as $\left.\left[\mathrm{bpy}^{2}\right] \mathrm{BF}_{+}\right]$ found to be an alternative to classical molecular solvents for alkylation of Meldrum's acid. ${ }^{30}$ IL was easily recovered and the yields of the reactions in recovered IL were not decreased even after repeated nuns. 
Table 3. Alkylation of Pyrrole with 1-Bromo-3-phenylpropane in the Presence of $\mathrm{K}_{2} \mathrm{CO}_{3}$ in Various lonic Liquids and $\mathrm{Co}$-solvents

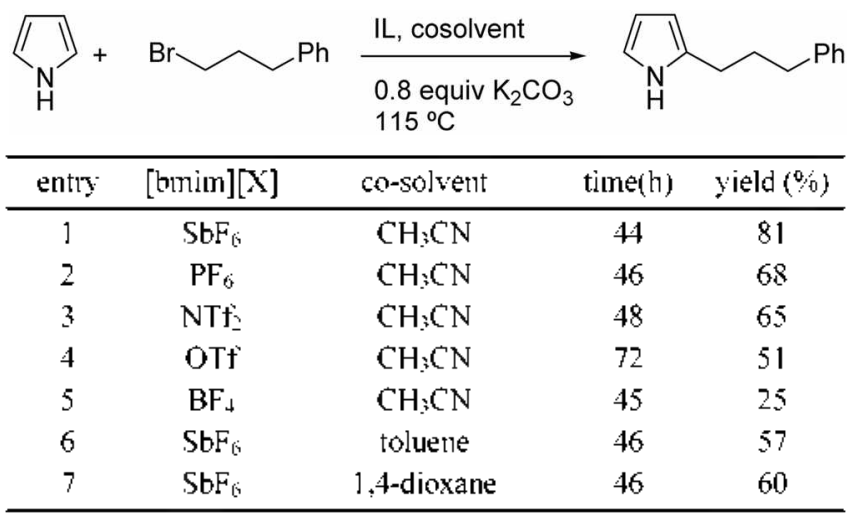

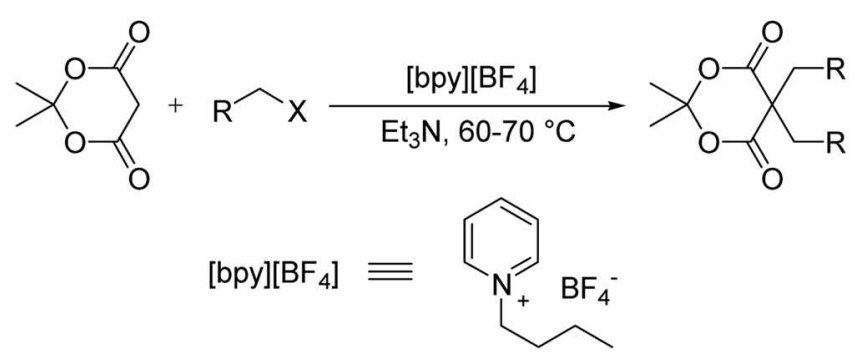

B. Pyrrole Alkylation. Pyrrole chemistry, particularly $C$ alkylation of pyrroles remains a challenge for the synthetic chemists because of its sensitivity to acids and air. ${ }^{31}$ However, ILs proved to be the best alternative as an environmentally benign media for pynole $C$-alkylation. Recently, we have achieved alkylation of pyrrole on $C 2$ or $\mathrm{C} 5$ position with various alkyl halides and mesylates in good yields with minimal byproducts under relatively mild conditions in various ILs (Table 3).32 The experimental procedure found to be simple and convenient, and in addition did not require any aqueous workup, thereby avoiding the generation of toxic waste.

C. Schiff Base Alkylation. A phase-transfer catalyst ${ }^{33}$ (PTC) facilitates the reaction between the organic reactant in the organic phase and the nucleophile in the aqueous phase as an inorganic salt. In a conventional reaction using PTC, the organic solvents such as dichloromethane or toluene as an environmentally undesirable media have been used. However, the use of the RTIL [bmim] $\left[\mathrm{PF}_{6}\right.$ ] as an efficient phase-transfer catalyst and solvent for several representative nucleophilic substitution reactions under aqueous-RTIL phase-transfer conditions have been explored by Nuno et $\mathrm{al}^{3+}$ The alkylations of $\mathrm{N}$-(diphenylmethylidene)glycine esters 1 and $\mathbf{2}$ were achieved using $\mathrm{KOH}$ in water-IL mixture solvent system as shown in Table 4. Further, they have studied other nucleophilic substitution reactions, which will be discussed later in Tables 12 and 13 .

\section{Carbon-Oxygen Bond Forming Reactions}

A. Hydroxylation. The displacement of various alkyl
Table 4. Alkylation of Schiff bases 1 and 2 using Aqueous-RTIL System

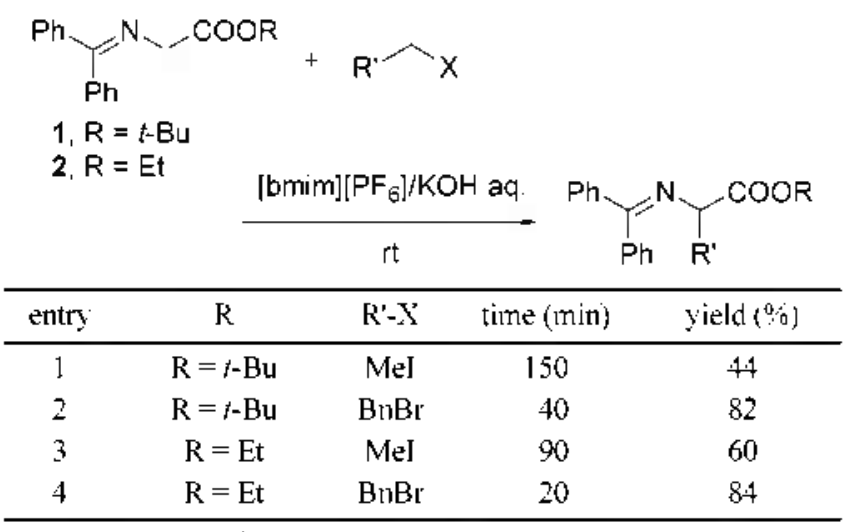

Reactions were prefonned in a two phase system containing aqueous KOI I solution ( $50 \%$, $0.5 \mathrm{~mL}$ ), [bmim] [PT 6 ] $11.0 \mathrm{~mL}$ ), $110.24 \mathrm{mmol}$ ) or 2 10.26 mol). alkyl halide 11.2 equiv), n. rigotous stirting.

halides and sulfonates by oxygen nucleophiles is wellstudied. Generally, a strong base or alkali metal hydroxide/ alkoxide with or without phase-transfer reagents is employed to generate oxygen nucleophiles. Also, these methods ${ }^{3,5}$ involve use of polar aprotic solvents such as dimethyl sulfoxide (DMSO), hexametlyyl phosphoric triamide (HMPA), or $N$-methylpyrrolidinone (NMP), But the above conditions often results in the fomation of the undesired elimination products, complication during work-up, separation, and purification steps. The first example of significantly enhanced nucleophilicity of water in ionic liquids to generate alcohol from alkyl halides in good to excellent yields have been reported by our group (Table 5). ${ }^{36}$

B. Metal Carbonate Alkylation. Utility of alkyl organic carbonates in the area of synthetic organic chemistry is wellrecognized. "Common synthetic methods leading to carbonates include use of classical toxic and hamful chemicals like phosgene, pyridine, and carbon monoxide. ${ }^{38}$ However, recently we have reported a new phosgene free method via alkylation of metal carbonates with various alkyl halides and sulfonates in $\left[\mathrm{bmim}^{-}\right]\left[\mathrm{PF}_{6}\right]$ as an eco-friendly reaction media (Table 6). ${ }^{39}$

This methodology was found to be simple and works well for all alkyl halides and sulfonates with the yield $>80 \%$.

Table 5. Hydroxylation of Bromoalkanc Using $\mathrm{H}_{2} \mathrm{O}$ in Various $\mathrm{ILs}^{\prime \prime}$

$\begin{array}{cccc} & & \mathrm{Br} & \text { water, 1,4-dioxane } \\ \text { ionic liquid, } 110{ }^{\circ} \mathrm{C}\end{array}$

"All reactions kere carried out on a 1.0 mmol reaction scale of bromoalkane using $1.5 \mathrm{~mL}$ of $\mathrm{I} \mathrm{I}, \mathrm{O}$ in $\Pi \mathrm{L}(4.0 \mathrm{~mL})$ and 1,4 -dioxane $\{2.5$ $m L$ ) at $110^{\circ} \mathrm{C}$. Tsolded vield. 
Table 6. Symmetrical Organic Carbonate Synthesis from 1-Bromo3-phenylpropane in the Presence of $\mathrm{K}_{2} \mathrm{CO}_{3}$ in Various ILs

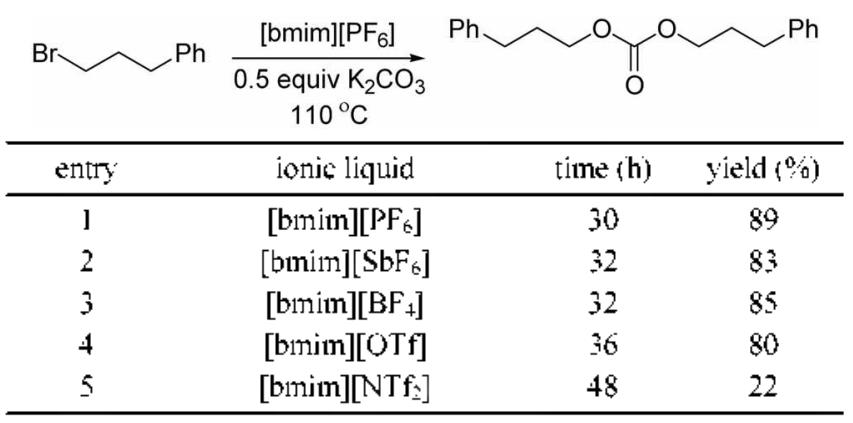

C. Peracetylation and Perbenzoylation. Peracetylation and perbenzoylation plays vital role in protection strategies, separation, and characterization of carbohydrates. ${ }^{+0}$ Acetic anhydride is the most widely used reagent for peracetylation and berzoyl chloride, well-known for its corrosiveness and pungent smell, for benzoylation of carbohydrates. ${ }^{+1}$ Toxic and odoriferous solvent, pyridine, is widely used as solvent/ catalyst in these reactions. However, recently dialkylimidazolium benzoates, room temperature ionic liquids (Figure 2. Table 7) were used in the peracetylation and perbenzoylation with excellent yields in short reaction times. ${ }^{+2}$

D. Ring Opening of Epoxides. Chlorohydrins and other halohydrins are an important class of organic compounds and versatile intermediates in the synthesis of a vast range of biologically active natural and synthetic products, unnatural amino acids, and chiral auxiliaries for asymmetric synthesis. The cleavage of epoxides was achieved with TMSCl in
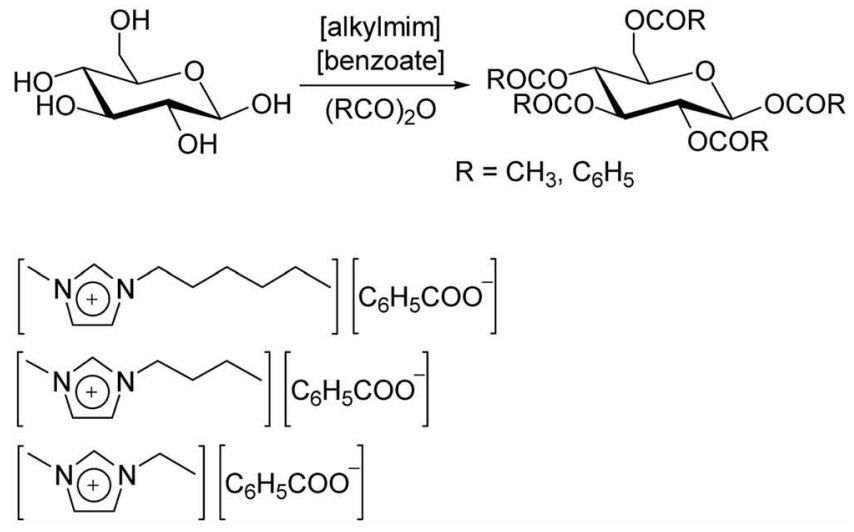

Figure 2 .

Table 7. Peracetylation and Perbenzoylation of Various Unsubstituted Saccharides in RTTLs at Roon Temperature

\begin{tabular}{|c|c|c|c|c|c|}
\hline entry & compound & $(\mathrm{RCO})_{2} \mathrm{O}$ & $\begin{array}{l}\text { [alkylinim] } \\
\text { [benzoate] }\end{array}$ & time $(h)$ & $\begin{array}{c}\text { yield }(\%) / \\
(\alpha, \beta)\end{array}$ \\
\hline 1 & /2-D-glucose & $A c O$ & [emim] & 4 & $100(0: 1)$ \\
\hline 2 & D-mannose & $\mathrm{Ac} O$ & [emim] & 3 & $78(1: 0)$ \\
\hline 3 & D-galactose & $A 0 \times O$ & [emim] & 4.5 & $71(1: 1)$ \\
\hline 4 & $\beta-\mathrm{D}$-glucose & $A c \approx O$ & [homim] & 7 & $68(1: 0.2)$ \\
\hline 5 & D-mannose & $(\mathrm{PhCO})_{2} \mathrm{O}$ & [emim] & 6 & $53(1: 0)$ \\
\hline
\end{tabular}

[bmim] $\left[\mathrm{PF}_{6}\right]$ ionic liquid ${ }^{+3}$ at ambient conditions. The advantages of the protocol include high yielding reaction that can be conducted at low temperature and fomation of high regio- and stereoselective ring opened products under environmental benign conditions.

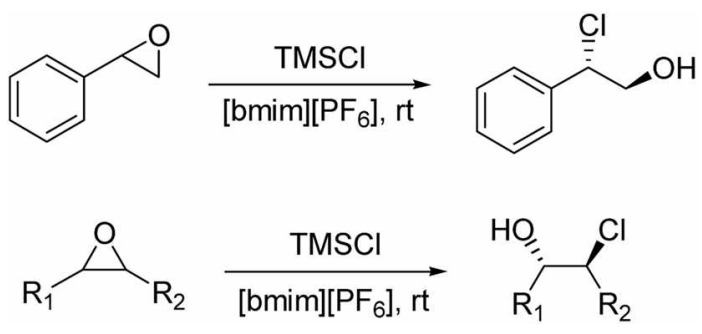

Song et al. achieved Co(III)(salen)-catalyzed hydrolytic kinetic resolution of racemic epoxides in the presence of ILs. Selective teminal epoxide ring opening hydroxylations provided $89.0-91.9 \%$ ee of diols and remained $>99 \%$ ee of chiral epoxides using $0.5 \mathrm{~mol} \%$ of Jacobsen's catalyst 3 . The mole ratio of epoxide:watercatalyst was 1.0:0.7:0.005.4

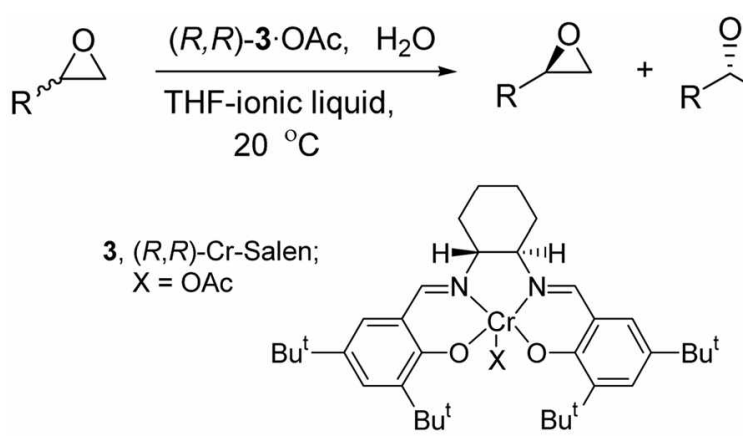

\section{Carbon-Nitrogen Bond Forming Reactions}

A. $N$-Alkylation. For the alkylation of less nucleophilic indole or 2-naphthol, dipolar aprotic solvent such as DMF or DMSO is generally used in the presence of stiochiometric amount of strong bases such as $\mathrm{NaH}$ or alkyllithiums. However, the relatively high boiling points of these solvents, their themal instability, and the environmental issues have been made their overall usage on the downside. Seddon et $\mathrm{al}^{+6}$ investigated and well utilized the unique behavior of IL in the regioselective alkylation of indole and 2-napluthol. They reported quantitative yields with the ease of IL recovery.

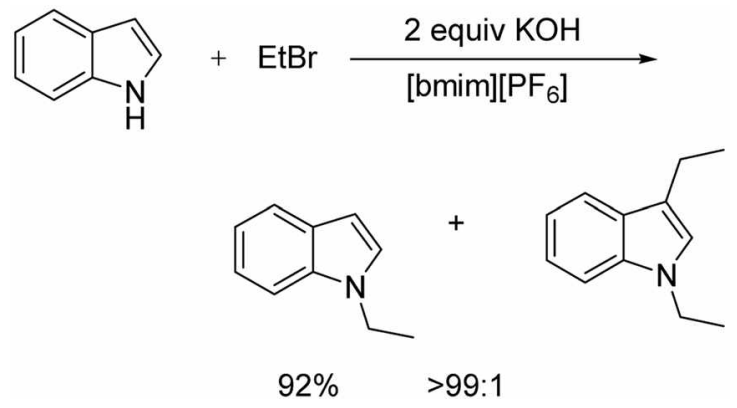


B. $N$-Benzylation. Shieh et al. found that jonic liquids could effectively accelerate the slow $N$-benzylation reactions utilizing dibenzyl carbonate as an alkylating reagent. ${ }^{.7}$ This methodology was a replacement for hazardous reagent such as carcinogenic benzyl chloride and lachrymose benzyl bromide. ${ }^{+8}$ Excellent yields of $80-90 \%$ were observed in ammonium-type ILs over imidazolium-type ones.

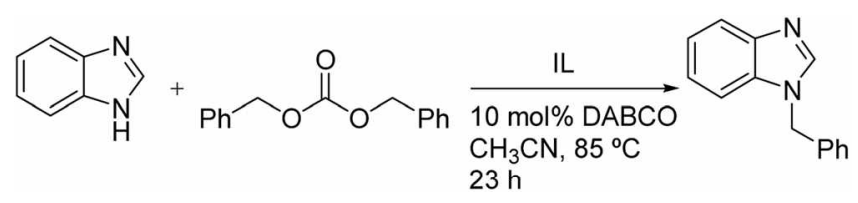

Further, Shieh $e t$ al. observed additional enhancements in the reaction rate from hours to minutes by applying microwave iradiation in the presence of the same IL.

Recently, our group developed the very mild methodology for the $\mathrm{N}$-alkylation of indole and pyrrole using potassium carbonate in $[\mathrm{bmim}]\left[\mathrm{BF}_{4}\right]$ as the sustainable reaction media with acetonitrile as the cosolvent. ${ }^{+9} N$-alkylation in IL provides good yields with alkyl halides as well as sulfonates as the electrophiles. Cesium carbonate was also found to be a consistent base in the $N$-alkylation.

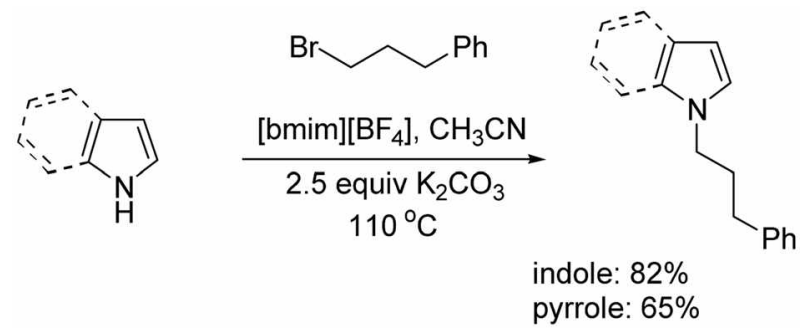

C. Ring Opening of Epoxides. Epoxides underwent smooth ring-opening with aryl amines in ionic liquids, [bmim] $\left[\mathrm{BF}_{\downarrow}\right]$, or $[\mathrm{bmim}]\left[\mathrm{PF}_{6}\right]$, under mild and neutral conditions to afford the corresponding $\beta$-amino alcohols in excellent yields with high regioselectivity. ${ }^{50}$ Utilization of ionic liquids as promoters for this transformation avoids the use of moisture sensitive and heavy metal Lewis acids.

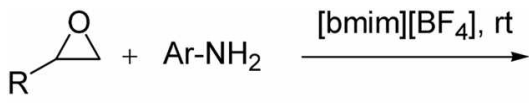

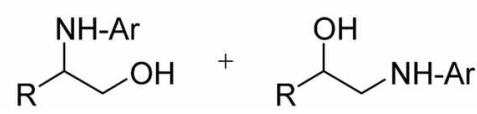

Cr-salen catalyzed ${ }^{t \prime}$ asymmetric ring opening reactions of epoxides with TMSN $_{3}$ proceeded readily in the room temperature ionic liquid 1-butyl-3-methylimidazolium salts [bmim] $[\mathrm{X}]$ with easy catalyst/solvent recycling (Table 8).

This methodology does not include hazardous workup stages such as distillation of the azide product, and moreover, provides not only simple recycling of catalyst but also the additional advantage that the catalyst can be used without any modification of the structure.
Table 8. Cr-Salen Catalyzed Ring Opening of Epoxides Carried out in Ionic Liquids
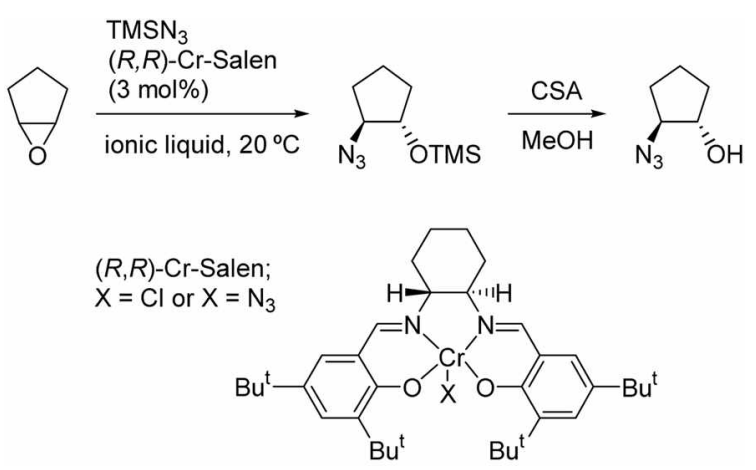

\begin{tabular}{|c|c|c|c|c|}
\hline entiy & ionic liquid & time $(\mathrm{h})$ & yield $(0 ; 0)$ & $\mathrm{ee}(0,0)$ \\
\hline 1 & {$\left[\right.$ bmim] $\left[\mathrm{PF}_{6}\right]$} & 28 & 76 & 94 \\
\hline 2 & {$\left[b_{i n i m}\right]\left[\mathrm{SbF}_{6}\right]$} & 28 & 75 & 87 \\
\hline 3 & {$[$ bmim $]\left[\mathrm{BF}_{4}\right]$} & 28 & 5 & 3 \\
\hline 4 & {$[$ binim $][\mathrm{OTf}\rceil$} & 28 & trace & - \\
\hline
\end{tabular}

\section{Carbon-Fluorine Bond Forming Reactions}

A. Fluorination by Nucleophilic Substitution. Due to their unique biological significance as a bioisostere for hydrogen, fluorine containing compounds have gained high potential past many decades. ${ }^{32}$ The nucleophilic displacement of various sulfonates and halides by fluoride is the typical method for the introduction of a single fluorine atom into aliphatic organic compounds. ${ }^{35}$ However, lack of solubility of alkali metal fluoride in organic solvent and low nucleophilicity made it unfavorable methodology. PTC proved to be less efficient particularly, tetra- $n$-butylammonium fluoride (TBAF) led to elimination and hydroxylation. Due to the basicity of fluoride, the eliminated olefin product is formed and an inevitable water inpurity of TBAF played a role of a nucleophile providing hydroxylated product. Recently, our group ${ }^{54}$ proved the significantly enlanced reactivity and selectivity of alkali metal fluoride using IL as a reaction media (Table 9 ).

The fluorination of 2-(3-methanesulfonyloxypropoxy)-

Table 9. Fluorinations of Mesylate with KF in ILs

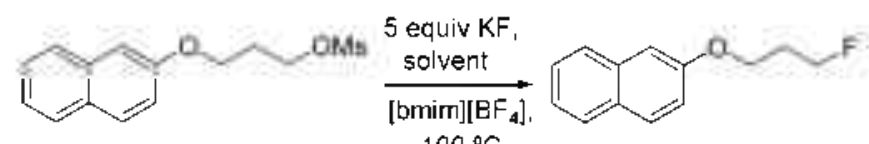
$100^{\circ} \mathrm{C}$

\begin{tabular}{|c|c|c|c|}
\hline entry & Ionic liquids & time (h) & yield $(0)^{b}$ \\
\hline 1 & {$[$ binim $]\left[\mathrm{BF}_{4}\right]$} & 1.5 & 94 \\
\hline 2 & {$[\mathrm{bmim}]\left[\mathrm{PF}_{6}\right]$} & 2 & 90 \\
\hline 3 & {$[$ bmim $]\left[\mathrm{SbF}_{6}\right]$} & 2 & 93 \\
\hline 4 & {$[$ bmim $][\mathrm{OTf}]$} & 4 & 79 \\
\hline 5 & {$\left[\right.$ bmim] $\left.\mathrm{NTf}_{2}\right]$} & 5 & 35 \\
\hline 6 & 18-crown-6 & 24 & 40 \\
\hline
\end{tabular}

“All reactions were cartied out on a $1.0 \mathrm{~mm}$ m reacion scale of mesylate. Isolated yield. 
Table 10. Fluorinations of Mesylate with Various Metal Fluorides in [biritit] $\left[\mathrm{BF}_{4}\right]$

\begin{tabular}{|c|c|c|c|}
\hline \multirow[b]{3}{*}{ entry } & \multirow[t]{2}{*}{ costs } & \multicolumn{2}{|l|}{$\begin{array}{l}5 \text { equiv MF } \\
{[\mathrm{bmim}]\left[\mathrm{BF}_{4}\right]}\end{array}$} \\
\hline & & $\begin{array}{l}\mathrm{CH}_{3} \mathrm{CN}\left(5 \% \mathrm{H}_{2} \mathrm{O}\right) \\
100^{\circ} \mathrm{C}\end{array}$ & \\
\hline & $\mathrm{MF}$ & time $(h)$ & $y$ ield $(\%)$ \\
\hline 1 & KF & 1.5 & 94 \\
\hline 2 & $\mathrm{RbF}$ & 30 min & 93 \\
\hline 3 & $\mathrm{CsF}$ & 20 min & 95 \\
\hline 4 & $\mathrm{AgF}$ & 48 & 5 \\
\hline
\end{tabular}

naphthalene with potassium fluoride in the presence of [bmim] $\left[\mathrm{BF}_{+}\right]$ionic liquid proceeded well at $100^{\circ} \mathrm{C}$ within $1.5 \mathrm{~h}$ to generate $94 \%$ of 2 -(3-fluoropropoxy)naphthalene (Table 9). In this methodology, IL not only enhanced the nucleophilicity of KF but also reduced the formation of byproducts such as alkenes and/or alcohols. Furthermore, we have observed good nucleophilicity of alkali metal fluorides, particularly $\mathrm{CsF}$, which found to be most reactive (Table 10),

However, alkali earth and transition-metal fluorides found to be of less useful in fluorination. Aromatic fluorinations in ILs were also studied by our group. ${ }^{56}$ Fluorination of I-(4acetylphenyl)-3,3-(pentanediyl)triazene $(1.0 \mathrm{mmol})$ and $p$ toluenesulfonic acid (1.2 mmol) in an ionic liquid, 1-butyl-3methylimidazolium tetrafluoroborate $\left([\mathrm{bmim}]\left[\mathrm{BF}_{+}\right], 2.5\right.$ $\mathrm{mL}$ ) proceeded very smoothly at $80^{\circ} \mathrm{C}$ with or without an extemal source of fluoride, providing $73 \%$ yield in $30 \mathrm{~min}$. We have also demonstrated various facile nucleophilic substitutions such as halogenations, acetoxylation, nitrilation, and alkoxylations, which will be discussed in Table 14.

B. $\left[{ }^{18}\right.$ F $]$ Fluorination for Radiopharmaceuticals. 2$\left[{ }^{18}\right.$ F]Fluoro-2-deoxy-d-glucose $\left(\left[{ }^{18} \mathrm{~F}\right] \mathrm{FDG}\right)$ is the most widely used radiopharmaceutical for positron emission tomography (PET). Recently, new [ ${ }^{18}$ F]FDG syntheses without a distillation step have been reported. "The fluorination was performed in an IL containing medium. The method was found to be rapid and straight forward and can be achieved by eliminating all evaporation steps. The ${ }^{18} \mathrm{~F}$ fluorination proceeded with a labeling efficiency of $74.6 \pm 7.4 \%(n=8)$ for optimized conditions.

Another application of ILs in the field of radiopharmaceuticals was reported by our research group as shown in Table 11. ${ }^{\$}$ We have demonstrated a process for effecting nucleophilic $\left[{ }^{18} \mathrm{~F}\right] \mathrm{fl}$ uorination of some halo- and mesyloxyalkanes to the corresponding $\left[{ }^{18} \mathrm{~F}\right]$ fluoroalkanes using $\left[{ }^{18} \mathrm{~F}\right]-$ fluoride ion and $\mathrm{Cs}_{2} \mathrm{CO}_{3}$ in [bmim][OTf] in the presence of appropriate amount of water. This method not only provides the product rapidly in good yield and high effective specific activity, but it is particularly convenient because it tolerates a certain amount of water. Thus, $\left[{ }^{18} \mathrm{~F}\right]$ fluoride in water, as obtained from the production target, can be added directly to the reaction media without having to be dehydrated, which is typically a time-consuming step required in other radiotluorination methods.
Table 11. Fluorination of Mesylate in [bmim][OTf] under Various Reaction Conditions

\begin{tabular}{|c|c|c|c|c|c|c|}
\hline entry & $\begin{array}{c}{ }^{18} \mathrm{~F}^{-} / \mathrm{H}_{2} \mathrm{O} \\
(\mu \mathrm{L})\end{array}$ & base & $\begin{array}{l}\text { time } \\
\text { (min) }\end{array}$ & $\begin{array}{l}\text { temp } \\
\left({ }^{\circ} \mathrm{C}\right)\end{array}$ & $\begin{array}{l}\text { radio TLC } \\
\text { yield }(0 \%)\end{array}$ & yield" $(0)$ \\
\hline 1 & 50 & $\mathrm{~K}_{2} \mathrm{CO}_{3}$ & 20 & 120 & 91 & 80 \\
\hline 2 & $50-60$ & $\mathrm{KHCO}$ & 30 & 20 & $98.7 \pm 1.6$ & $82 \pm 0.4$ \\
\hline 3 & $50-60$ & $\mathrm{Cs}_{2} \mathrm{CO}_{3}$ & $5-10$ & 120 & $97.6 \pm 0.9$ & $93 \pm 1.2$ \\
\hline 4 & 250 & $\mathrm{Cs}_{2} \mathrm{CO}_{3}$ & 20 & 120 & 90 & 85 \\
\hline 5 & 250 & $\mathrm{KHCO}$ & 60 & 140 & 28 & 26 \\
\hline 6 & {$\left[{ }^{18} \mathrm{~F}\right] \mathrm{TBAF}$} & - & $15-20$ & 110 & $85.3 \pm 6.4$ & $72 \pm 10.8$ \\
\hline
\end{tabular}

"Tsolated yield after decay correction.

\section{Other Nucleophilic Displacement Reactions}

Afonso's group ${ }^{34}$ studied the effect of IL for phenoxide, iodide, cyanide, and azide displacements. Significantly enhanced nucleophilicity was observed with catalytic amount of RTIL. They applied this methodology to various alkyl halides to generate corresponding ethers, iodides, nitriles, and azides as shown in Tables 12 and 13. Further, they have found that the recycling and reuse of the [bmim] $\left[\mathrm{PF}_{6}\right]$ is feasible for the azide fomation with a yield $>94 \%$ for each cycle.

The nucleophilic substitution reactions such as halogenations, acetoxylation, nitrilation, and alkoxylations in ILs were also well studied by our group. ${ }^{57}$ As shown in Table 14 , halogenations completed within $30 \mathrm{~min}$ at $100^{\circ} \mathrm{C}$ in [bmim] $\left[\mathrm{BF}_{4}\right]$ affording the desired compounds in $>90 \%$ yield. The nucleophilic acetoxylation of bromoalkane using potassium acetate at $25^{\circ} \mathrm{C}$ resulted in $95 \%$ of acetoxy compound in $\left[\mathrm{bmim}_{\mathrm{um}}\right]\left[\mathrm{BF}_{4}\right]$ ionic liquid. The same reaction was studied in various ILs with a yield above $90 \%$. The

Table 12. Effect of the [bmim] $\left[\mathrm{PF}_{6}\right]$ on Aqueous-dichloromethane Biphasic Nucleophilic Substitution Reactions on Benzyl Bromide

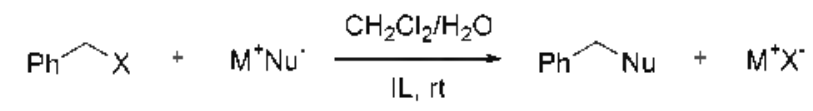

\begin{tabular}{ccccc}
\hline entry & $\begin{array}{c}\text { M Nu- } \\
\text { (equiv) }\end{array}$ & $\begin{array}{c}\text { [bnim][PF } \\
\text { (equiv) }\end{array}$ & $\begin{array}{c}\text { time } \\
\text { (h) }\end{array}$ & $\begin{array}{c}\text { conversion (\%) } \\
\text { (by 'H NMR) }\end{array}$ \\
\hline $1^{\prime \prime}$ & NaOPh (1.0) & - & 3 & 3 \\
$2^{4}$ & NaOPh $(1.0)$ & 0.5 & 3 & 80 \\
$3^{h}$ & $\mathrm{KCN}(2.0)$ & - & 16 & 5 \\
$4^{h}$ & $\mathrm{KCN}(2.0)$ & 0.5 & 16 & 47 \\
$5^{h}$ & $\mathrm{NaN}(2.0)$ & - & 5 & 37 \\
$6^{h}$ & $\mathrm{NaN}(2.0)$ & 0.5 & 5 & 90 \\
\hline
\end{tabular}

"Reaction was perfonted in a wo phase system containing $\mathrm{NaOH} 16.0$ equis) in water $(1.0 \mathrm{~mL})$, phenol $11.0 \mathrm{mmol})$, and benzyl bromide 11.2 equiv) in dichloromethane $(0.5 \mathrm{~mL}$ ) with vigorous stirring. "Reaction Has perfoned in a tho phase system containing KCN or NaN-12.0 equir) in valer $11.0 \mathrm{~mL})$. and benzyl bromide 11.0 equiv) in dichloromethane $(0.5 \mathrm{~mL})$ with vigorous stirring. 
Table 13. Nucleophilic Substitution Reactions on Various Alkyl Halides in Aqueous-RTTL System

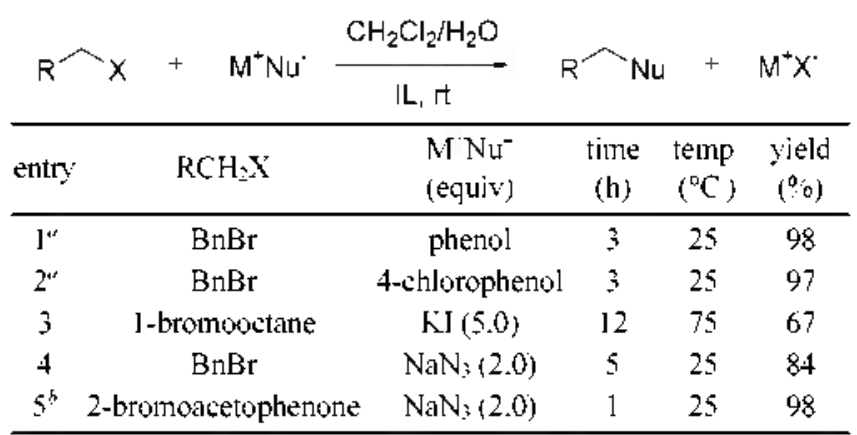

"Reaction was performed in a 1 wo phase system containing $\mathrm{NaOH}(6.0$ equiv) in water $(1.0 \mathrm{~mL})$, phenol or + -chlorophenol $(1.0 \mathrm{mmol})$, and berlasl bromide $\left(1.2\right.$ equiv) in [bmim] $\left[\mathrm{BF}_{4}\right](0.5 \mathrm{~mL})$ with vigorous stirring. "Reaction was perlorned in a two phase system conlaining water $\left(1.0 \mathrm{~mL}\right.$ ). and [bmim] $\left[\mathrm{BF}_{4}\right](0.5 \mathrm{~mL})$ with vigorous stirring.

Table 14. Nucleophilic Substitutions with Various Potassium Salts in $[\mathrm{bmim}]\left[\mathrm{BF}_{4}\right]$

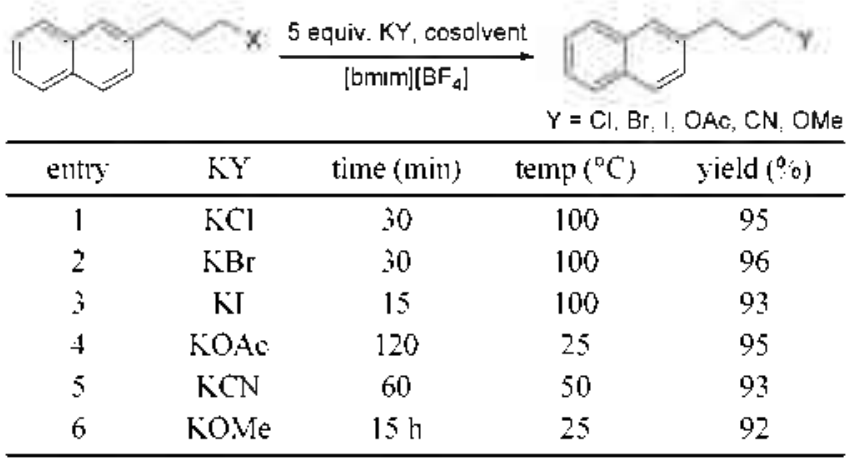

nitrilation using potassium cyanide, which did not occur in acetonitile even after $48 \mathrm{~h}$ at $100^{\circ} \mathrm{C}$, whereas the same reaction proceeded well in $[\mathrm{bmim}]\left[\mathrm{BF}_{+}\right]$within $\mathrm{I} \mathrm{h}$ at $50^{\circ} \mathrm{C}$ with a yield of $93 \%$. The methoxylation, which usually was preformed under basic conditions resulting in eliminated compound, provided $92 \%$ of methoxylated compound in IL at $25^{\circ} \mathrm{C}$ within $15 \mathrm{~h}$.

The use of RTILs as envirommentally benign solvents for the cyanide displacement on benzyl chloride replacing phase-transfer catalyzed biphasic systems has been demonstrated by Wheeler et al ${ }^{5}$

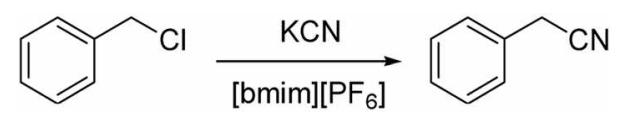

Reactions were canied out at 40,60 , and $80^{\circ} \mathrm{C}$, and were carefully monitored for analysis by HPLC equipped with a UV-Visible detector.

Phenacyl esters, attractive protecting groups, which are stable to many reactive conditions used in organic synthesis and can be released under very mild conditions such as zinc in acetic acid. The utility of IL to accelerate the nucleophilicity of potassium salts of aromatic acids toward $\alpha$ aryloxy ketone synthesis is recently been explored by Chen and co-workers. ${ }^{60}$

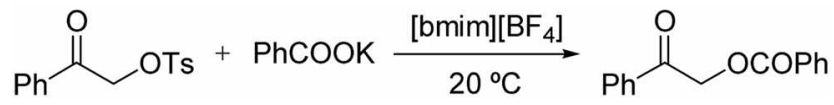

The same group also reported one-pot procedure for the preparation of $\alpha$-aryloxy ketones by oxidation of ketones with [hydroxy(tosyloxy)iodo]benzene (HTDB) and nucleophilic substitution with potassium salts of aromatic acids in IL.

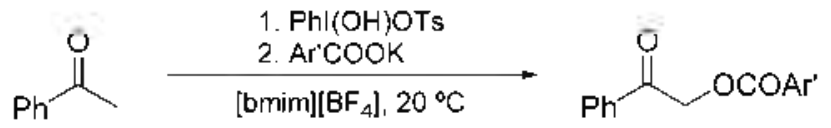

Another nucleophilic displacement reaction involving chloride displacement on benzyl chloride by benzyl salicylate at room temperature in ILs is documented by Judeli et $a l^{6]}$ The reaction was found to proceed with an excellent conversion up to $96 \%$.<smiles>[NH3+]OC(=O)c1ccccc1OCc1cccc(C(=O)OCc2ccccc2)c1O</smiles>

Chiappe $e t \mathrm{Cl}_{+}^{62}$ studied substrate and solvent effect in the reaction of sodium azide and potassium cyanide with alkyl halides and tosylates in RTILs as environmentally benign solvents. Primary, secondary, and tertiary azides were obtained in high yields without any elimination byproducts.

$$
\begin{aligned}
& R-X \frac{M Y, 80^{\circ} \mathrm{C}}{\mathrm{IL}} \mathrm{R}-\mathrm{Y} \\
& X=\mathrm{Cl}, \mathrm{Br}, \mathrm{I}, \mathrm{OTs} \\
& M Y=\mathrm{NaN}_{3}, \mathrm{KCN}
\end{aligned}
$$

Recently, Welton's group used a series of 1-butyl-3methylimidazolium ionic liquid for the study of anion effects on halide nucleophilicity. ${ }^{63}$ The reaction was studied with methyl $p$-nitrobenzenesulfonate as a model compound with the halide to give methyl halide and $p$-nitrobenzenesulfonate anion.<smiles></smiles>

It was found that the nucleophilicities of all the halides were lower in all of the ILs than in dichloromethane. Changing an anion affected the order of halide nucleophilicity, $e g_{4}$, in [bmim] $\left[\mathrm{BF}_{4}\right]$ the order of nucleophilicity was $\mathrm{Cl}^{-}>\mathrm{Br}^{-}>\mathrm{I}^{-}$whereas in [hmim] [NTfin the order was $\mathrm{Cl}^{-}<\mathrm{Br}^{-}<\mathrm{I}^{-}$. Their studies came up with the conclusion that the reaction in the ILs has a high activation free energy barrier, due to the solvent-solute interactions within the ILs. 
Table 15. Reaction of Nucleophiles with $[\mathrm{bmim}]\left[\mathrm{BF}_{4}\right]$ under Microwave Heating

\begin{tabular}{ccccc}
\hline entry & temp $\left({ }^{\circ} \mathrm{C}\right)$ & Nuc & Nuc-Me $(\%)$ & Nuc-Bu $(\%)$ \\
\hline 1 & 225 & PhSH & 5 & 1 \\
2 & 225 & NaSPh & 39 & 7 \\
3 & 125 & NaSPh & 16 & 1 \\
4 & 225 & $\mathrm{PhCO}_{2} \mathrm{Na}$ & 27 & 13 \\
5 & 225 & $\mathrm{PhNH}_{2}$ & 4 & 1 \\
6 & 225 & $\mathrm{PhONa}$ & 2 & trace \\
\hline
\end{tabular}

Further, Crowhurst et al. reported the effect of ILs on a class of charge-neutral nucleophiles. ${ }^{6+}$ The reactions of $n$ butylamine, di-n-butylamine, and tri-n-butylamine with $p$ nitrobenzenesulfonate in [bmpy][NTf $f_{2}$, [bmpy][OTf], and $[\mathrm{bmim}][\mathrm{OTf}]$ and their rate behavior was well-investigated in comparison with molecular solvents dichloromethane and acetonitrile. With IL the activated complex formation from the charge-neutral species was observed.

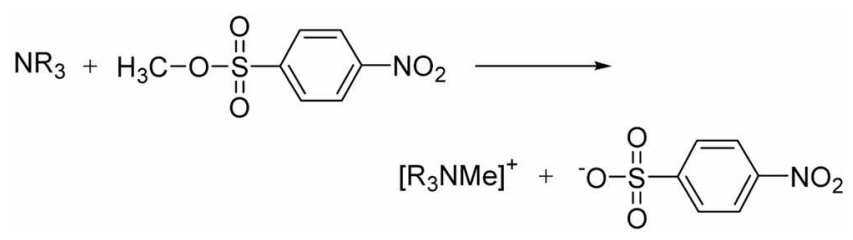

In addition, Lancaster recently reviewed organic reactivity in ionic liquids with some mechanistic insights into nucleophilic substitution reactions. ${ }^{65}$ The principal findings of studies on nucleophilic substitutions in ionic liquids are reviewed. The review mentioned that there have been few other quantitative studies of nucleophilic substitutions in ionic liquids. These data are compared to related reactions in molecular solvents, and used to show, where ionic liquids do (and do not) offer advantages over molecular solvents for nucleophilic substitutions. Although many experimantal results were obtained with better yields in nucleophilic substitution reactions from our group and other groups, there has been a controversy regarding the enhancement of nucleophilicity in ionic liquid.

ILs are known to be relatively inert and tolerate a variety of chemical transformations. Mostly it is found to have significant number of applications in nucleophilic substitution reactions. However, its sustainability at a high temperature under microwave conditions is in doubt. Recently, an uncommon decomposition of $N N^{t}$-dialkylimidazolium cation through the $S_{>} 2$ attack of the nucleophile on the electrophilic alkyl groups attached to the imidazoline ring under microwave heating has been reported (Table 15), ${ }^{66}$

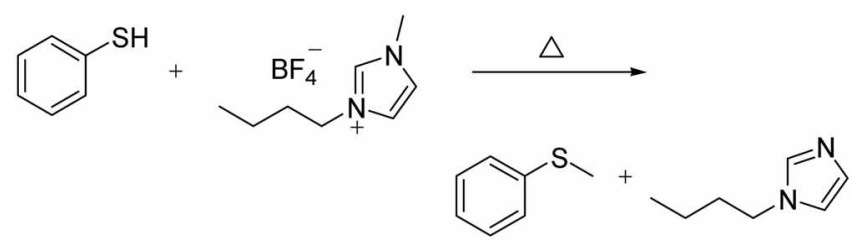

They have also observed in some cases significant quantities of substitution products even at the temperature of $125^{\circ} \mathrm{C}$

\section{Conclusions}

In conclusion, this review is for those beginners, who are willing to have an in depth knowledge about reactions in ILs. Ionic liquid teclnology considered to be young chemistry, which has gained tremendous potential not only in organic synthesis but also in catalysis, biocatalysis, phammaceuticals, radiophamaceuticals, biotransfomation, and further spreading its web to each and every lab including academia and industry. Indeed, IL without any obstacle will find its way in many applications, where conventional organic solvents are used today. There still remains hidden and unique chemistry about ILs. We hope that the chemists, who are willing to adapt IL teclnology will find this review worthy.

Acknowledgement. This work was supported by National Research and Development Program of MOST, Korea (2005-03184).

\section{References}

1. (a) For a monograph on this subject, see: Hartshom, S. R. Aliphatic Nicleophific Substitution; Cambridge University Press: Cambridge, 1973. (b) For reviews, see: Katritzky, A. R.; Brycki, B. E. Chem. Soc, Rer. 1990, 19,83-105.

2. (a) Cowdrey, W. A.; Hughes, E. D.: Ingold, C. K.; Masteman, S.; Scou, A. D. J. Chem. Soc. 1937, 1252-1271. (b) Lewis, G. N. Falence and the Structue of Atoms and Molecules: Chemical Catalog Company: NY, 1993; p 113. (c) Olsen. A. R. J. Chen. Phr. 1933, $1,418-423$. (d) Waldet, P. Ber. 1893, 26, 210. (e) Walden, P. Ber. 1896, 29, 133. (f) Walden, P. Ber. 1899, 32, 1855.

3. (a) Yost, M. G.: Rose, M. A.; Morgan, M. S. Appl. Occup. Envon. Hyg. 2003, 1S, 160-169. (b) Welles, W. L.: Wilburn, R. E.: Ehrlich, J. K.; Floridia, C. M. J. Hazard Hater 2004, 1/5, 3949. (c) Tsai, J.-H.; Hsu, Y.-C.,; Yamg, J.-Y. Sci. Tork Envor. 2004, 32.9, 131-142. (d) Agostitui, E.; Chini, M.; Ciucci, I.; Corezzi, M.; Mazzini, M. Adr, Air Pollth. 2004, 14, 647-656.

4. For recent reviews on ionic liquids, see: (a) Sheldon, R. Chem. Commut, 2001, 2399-2407, (b) Zhao, H.: Malhotra, S. V. Addichinica Acta 2002, 35, 75-83. (c) Wasserscheid, P.; Keim, W. Angen: Chem, Int Ed. Engl. 2000, 39, 3772-3789. (d) Welton, T. Chem. Ren: 1999, 99, 207/-2083. (d) Jain, N.; Kunnar, A.; Chauhat, S.; Chauhan, S. M. S. Terwhedron 2005, 01, 10151060. (e) Baudequin, C.: Baudoux, J.: Levillain, J.; Cahard, D.; Gaumont, A.-C.: Plaquevent, J.-C. Temahedron: Asymmeny 2003 , 14, 3081-3093. (f) Dupont, J.; deSouza, R. F. Suarez, P. A. Z. Chent. Rev, 2002, J02, 3667-3692. (g) Liu, J.-F.; Jōnsson, J. A.; Jiang, G.-B. Trends Anal, Chent. 2005, 24, 20-27. (h) Gordon, C. M. Appl. Catal. A Gen. 2001, 222, 101-117. (j) Holbrey, J. D.; Seddon, K. R. Clean Products Process 1999, 1, 223-226. (j) Wilkes, J. S. Green Chem. 2002, 4, 73-80. (k) For article on [bmim] [BF. ], sec: Jorapur, Y. R. Sylen 2004, 746-747. (l) For article on ILs, see: Rogers, R. D.; Seddon, K. R. Science 2003. $302,792-793$.

5. (a) Bothote, P.; Dias, A.-P.; Papageorgiou, N.; Kalyanasundaran, K.: Gratzl, M. Inorg. Chen. 1996, 35, I168-1178. (b) Hussey, C. L. Pure Appl. Chem. 1988, 60, 1763-1772. (c) Seddon, K. R. In Molten Salt Chemistm: Mamantov, G.: Marassi, R., Eds.; Reidel 
Publishing Co.: Dordrecht, The Netherlands, 1987; p 365. (d) Wilkes, I. S.; Levisky, I. A.; Wilson, R. A.; Hussey, C. L. Inorg. Chem. 1982, 21, 1263-1264. (e) Hussey, C. L. In Adrances in Molten Salts Chemistry: Mamantov, G.; Mamantov, C., Eds.; Elsevier: New York, 1983; Vol. 5, pp 185-230. (1) Dieter, K. M.; Dymek, C. J.; Heimer, N. E.; Rovang J. W.; Wilkes, J. S. J. Am. Chem. Soc. 1988, 110, 2722-2726. (g) \igo, H. L.; LeCompte, K.; Hargens, L.; McEwen, A. B. Thermochm. Acto 2000, 357-358, $97-102$.

6. (a) Freemantle, M. Chen. Eng. Nens 1998, 70, 32-37. (b) Hagiwara, R.; Ito, Y. J. Fluorine Chem. 2000, 105, 221-227.

7. (a) Song, C. E.; Yoon, M. Y.; Choi, D. S. Bull. Korean Chem. Soc. 2005, 26, 1321-1330, (b) Song C. E. Ann. Rep. Prog. Chem. Sect. C. 2005, 101, 143-173. (c) Song. C. E. In Methodologies in Asymmetric Catalysis, ACS-Symposium Series 880; Malhotra, S. V., Ed.; 2004; pp 145-160. (d) Song, C. E. Chem. Commum. 2004, $1033-1043$

8. Sun, J.; Forsyth, M.; MacFarlane, D. R. J. Phy: Chem. B 1998, I02, 8858-8864.

9. Mujatake, K.: Yamaınoto, K.: Endo, K.: Tsuchida, E. J. Org. Chem. 1998, 63, 7522-7524.

10. Kim, H. S.; Kim, Y. I.; Bae, I. Y.: Kim, S. J.; Lah, M. S.; Chin, C. S. Organometallics 2003, 22, 2498-2504.

11. (a) Dzzuba, S. V.; Barsch, R. A. Chem. Phys. Chem. 2002, 3, 161166. (b) Huddleston, J. G. Visser, A. E.; Reicher, W. N.; Willauer, H. D.; Broker, G. A.; Rogers, R. D. Green Chem. 2001, 3. 156-164. (c) Grodkowski, J.: Neta, P. J. Phy. Chem. A 2002, 106, 11130-11134. (d) Grodkowski, I.; Neta. P. J. Phys. Chem. A 2002, 106, 5468-5473, (e) McLean, A. J.; Muldoon, M. J.; Gordon, C. M.; Dunkin, I. R. Chem. Commun, 2002, 1880-1881, (1) Owens, G. S.; Abu-Omar, M. M. J. Mol. Catal. A: Chem. 2002, $187,215-225$.

12. Tait S.; Osteryoung, R. A. Ihorg. Chem 1984, 23, 4352-4360.

13. MacFarlane, D. R.; Meakin, P.; Sun, I.; Amini, N.; Forsyth, M. $J$. Phos. Chem. B 1999, 10s, 4164-4170.

14. Davis, J. H. Jr.; Fortester, K. J. Tetrahedron Lett. 1999, 40, 1621 1622 .

15. Vestergaard, B.: Bjerrum, V. T.; Petrushina, I.; Hjuler, H. A.; Berg, R. W.; Begtrup, M. J. Electrochen. Soc, 1993, /40,3108-3113.

16. Tomoharu, $N$. Sanyo Chem. Ind. Ltd.: JP $11273734,1999$.

17. Mamantov, G. J. C.; Dunstan, T. D. J. Electrochemical Systems Inc.: U.S. Palent 5552241, 1996.

18. Wilkes, J. S.; Zaworolko, M. J. J. Chem. Soc., Chem. Commun. 1992, 965-967.

19. Fuller, J.; Carlin, R. T.; De Long, H. C.; Haworth, D. J. Chem. Soc. Chem. Commin. 1994, 299-300.

20. Howarth, J.; Hanlon, K.; Fayne, D.; McCormac, P. Tetrohedron Lett, 1997, 3S, 3097-3100.

21. Chauvin, Y.; Mussmann, L.; Olivier, H. Anger: Chem., Int. Ed. Engl. 1995, 34, 2698-2700.

22. Chauvin, Y; Oliver-Bourbigou, H. CHEWTECH 1995, 26-30.

23. Koch, V. R.; Dominev, L. A.; Vanjundiah, C.; Ondrechen, M. T. $J$. Electrochem. Soc. 1996, $143,798-803$.

24. Nanjundiah, C.; McDevill, S. F.; Koch, V. R. J. Electrochem. Soc. 1997, 144, 3392-3397.

25. Nitta, K.: Murase, K.: Matsumoto, H.; Mivazaki, Y.: Hirato, T.; Awakura, Y. Kidorti 1998, 32, 270-271.

26. Koch, V. R.; Nanjundiah, C.: Appetechi, G B.; Scrosati, B. J. Electrochem. Soc. 1995, 142, L116-L118.

27. Kempernan, G. J.; Roeters, T. A.; Hilberink, P. W. Eur. J. Org. Chem. 2003, 1681-1686.

28. Boovanahalli, S. K.: Kim, D. W.: Chi, D. Y. J. Org. Chem. 2004. $69.3340-3344$.

29. Chan, C. C.: Huang, X. Synthesis 1982, 452-454.

30. Su, C.: Chen, Z.-C.; Zheng, Q.-G. Symth. Commun. 2003, 33, $2817-2822$.

31. (a) Belen'kii, L. I. Heterocycles 1994, 37, 2029-2049. (b) Reinecke, M. G.; Johnson, H. W.; Sebastian, I. F. J. An. Chem.
Soc. $1963,85,2859-2860$.

32. Jorapur, Y. R.; Lee, C.H.; Chi, D. Y. Org. Lett. 2005, 7, 1231 1231.

33. (a) Starks, C. M.; Liotta, C. L.; Halpern, M. Phose-Tronsfer Catalysis: Charpman and Hall: NY, 1994. (b) O'Donnell, M. J.; Esikova, I. A.; Mi, A.: \$hullenberger, D. F.; Wu, \$. In PhaseTransfer Catalysis, ACS Symposium Series 659: Halpem, M. E., Ed.; American Chemical Society: Washington, DC, 1997; Chapter 10. (c) Nelson, A. Angen: Chem. Int. Ed. 1999, 38, 1583-1585.

34. Lourenco, N. M. T.; Afonso, C. A. M. Tetrathedron 2003, 59, $789-$ 794.

35. (a) Martin, D.: Weise, A.; Niclas, H. Angen: Chem. Int Ed. Engl. 1967, 6, 318-334. (b) Nomant, H. Angew: Chem. Int. Ed. Engl. $1967,0,1046-1067$.

36. Kim, D. W.; Hong, D. J.; Seo, J. W.; Kim, H. S.; Kim, H. G.; Song, C. E.; Chi, D. Y.J. Org. Chem. 2004, 69, 3186-3189.

37. (a) Shailh, A.-A. G.; Sivaram, S. Chem. Rer. 1996, 96, 951-976. (b) Rolf, K.; Achim, A.: Holger, T.: Gabrille, S.: Alfred, W. Ger. Offen. DE 4119890,1991 ; Chem. Abstr 1993, $118,66614 \mathrm{q}$.

38. (a) Schnell, H. Chemistin and Phrsics of Polycarbonates; Interscience Publishers: New York, 1964; Vol. 9, p 91. (b) Kondo, K.; Sonoda, N.; Tsutsulni, S. Tetrahedron Lett. 1971, 12, 48854886. (c) Fenton, D. M.: Steinwand, P. J. J. Org. Chem. 1974, 39, $701-704$.

39. Jorapur, Y. R.; Chi, D. Y.J. Org. Chem. 2005, 70, 10774-10777.

40. Kerns, R. J.; Vlahov, I. R.; Limhardt. R. J. Carbohndr: Res, 1995, $267,143-152$.

41. Vogel, A. I. Vogels Texthook of Practical Organic Chentistry; 5th Ed.: Wiley: New York, 1984:p 644.

42. Murugesan, S.; Karst, N.: Islam, T.; Wiencek, J. M.: Linhardt, R. J. Synlett 2003, 1283-1286.

43. Xu, L.-W.; Li, L.; Xia, C.-G; Zhao, P.-Q. Tetrohedrom Lett. 2004. $45,2435-2438$

4. Oh, C. R.; Choo, D. J.; Shim, W. H.; Lee, D. H.; Roh, E. J.; Lee, \$.-g.; Song, C. E. Chem. Conmmin. $2003,1100-1101$.

45. (a) Nunomoto, S.: Kawakami, Y.: Yamashita, Y: Takeuchi, H.; Eguichi, S. J. Chem. Soc., Perkin Trans. I 1990, IIl-114. (b) Kombluin, N.; Seltzer, R.; Haberfield, P. J. Am. Chem. Soc 1963. 85, 1148-1154. (c) Cardillo, B.; Casnati, G.; Pochini, A.; Ricca, A. Tetrahedron 1967, 23, 3771-3783. (d) Heaney, H.; Ley, S. V. $J$. Chent. Soc., Perkin Trans. 1 1973, 499-500.

46. Earle, M. J.: McComac, P. B.: Seddon, K. R. Chent. Commun. $1998,2245-2246$.

47. Shieh, W.-C.; Lozanov, M.; Repi, O. Tetrathedron Lett. 2003, 44 , 69.13-69.15.

48. Shieh, W.-C.; Lozanov, M.; Loo, M.; Repi, O.; Blacklock, T. J. Tetrahedron Lett. $2003,44,4563-4565$.

49. Jorapur, Y. R.; Chi, D. Y. Tetrahedron Lett. 2006, 47, 2435-2438.

50. Yadav, J. S.: Reddy, B. V. S.: Basak, A. K.; Narsaiah, A. V. Tetrakedron Lett. 2003, 44, 1047-1050.

51. Song, C. E.; Oh, C. R.; Roh, E. J.; Choo, D. J. Chem. Conmurr. $2000,1743-1744$.

52. (a) Seebach, D. Angew: Chem., Int. Ed. Engl. 1990, 29, 13201367. (b) Gerstenberger, M. R. C.: Haas, A. Angen: Chem., hn. Ed. Engl. 1981, 20,647-667. (c) Mascaretti, O. A. Aldrichinica Acta 1993, 26, 47-58.

53. Liotta, C. L.; Harris, H. P. J. Am. Chem. Soc. 1974, 96, 22502252.

54. Kim, D. W.; Song, C. E.; Chi, D. Y.J. Am. Chem. Soc. 2002, 124, $10278-10279$.

55. Kim, D. W.; Song, C. E.: Chi, D. Y. J. Org. Chem. 2003, 68, 42814285 .

56. Chu, C.-K.; Kim, J.-H.; Kim, D. W.; Chung, K.-H.; Katzenellenbogen, J. A.; Chi, D. Y. Butl. Korear Chem. Soc 2005, 26, 599-602.

57. Kim, H. W.: Jeong, J. M.: Lee, Y.-S.: Chi, D. Y.: Chung, K.-H.; Lee, D. S.: Chung, J.-K.: Lee, M. C. Appl. Radiat. Isot. 2004, 61, $1241-1246$. 
58. Kim, D. W.; Choe, Y. S.; Chi, D. Y. Nud. Med. Biol. 2003, 30, 345-350.

59. Wheeler, C.: West K. N.; Liotta C. L.; Eckert C. A. Chem. Commin. 2001, 887-888.

60. Liu, Z.; Chen, Z.-C.; Zheng, Q.-G Symthesis 2004, $33-36$.

61. Judeh, Z. M. A.; Shen, H.-Y.; Chi, B. C.; Feng, L.-C.; Selvasolhi, S. Tetrahedron Lett, 2002, 43,9381-9384.

62. Chiappe, C.; Pieraccini, D.: Saullo, P. J. Org. Chem. 2003, 68,
$6710-6715$

63. Lancaster, N. L.; Salter, P. A.; Welton, T.; Young, G. B. J. Org. Chent. 2002, 67, 8855-8861.

64. Crowhurst, L.; Lancaster, N. L.; Pérez Arlandis, J. M.; Welton, T. J. An. Chem. Soc. 2004, $126,11549-11555$.

65. Lancaster, N. L. J. Chent. Res. $2005,413-117$.

66. Glenn, A. G; Jones, P. B. Tetrahedron Lett, 2004, 4.5, 69676969. 